University of Nebraska - Lincoln

DigitalCommons@University of Nebraska - Lincoln

Nutrition and Health Sciences -- Faculty

Publications

Nutrition and Health Sciences, Department of

8-2006

\title{
Validity and Reliability of a Quantitative Food Frequency Questionnaire Measuring n-3 Fatty Acid Intakes in Cardiac Patients in the Midwest: A Validation Pilot Study
}

\author{
Paula K. Ritter-Gooder \\ University of Nebraska-Lincoln, pgooder@windstream.net \\ Nancy M. Lewis \\ University of Nebraska--Lincoln, nlewis2@unl.edu \\ Kimberly B. Heidal \\ East Carolina University, heidalk@ecu.edu \\ Kent M. Eskridge \\ University of Nebraska - Lincoln, keskridge1@unl.edu
}

Follow this and additional works at: https://digitalcommons.unl.edu/nutritionfacpub

Part of the Dietetics and Clinical Nutrition Commons

Ritter-Gooder, Paula K.; Lewis, Nancy M.; Heidal, Kimberly B.; and Eskridge, Kent M., "Validity and Reliability of a Quantitative Food Frequency Questionnaire Measuring n-3 Fatty Acid Intakes in Cardiac Patients in the Midwest: A Validation Pilot Study" (2006). Nutrition and Health Sciences -- Faculty Publications. 15.

https://digitalcommons.unl.edu/nutritionfacpub/15

This Article is brought to you for free and open access by the Nutrition and Health Sciences, Department of at DigitalCommons@University of Nebraska - Lincoln. It has been accepted for inclusion in Nutrition and Health Sciences - Faculty Publications by an authorized administrator of DigitalCommons@University of Nebraska - Lincoln. 


\title{
Validity and Reliability of a Quantitative Food Frequency Questionnaire Measuring n-3 Fatty Acid Intakes in Cardiac Patients in the Midwest: A Validation Pilot Study
}

\author{
Paula K. Ritter-Gooder MS, RD, \\ Research assistant, Department of Nutrition and Health Sciences, University of Nebraska-Lincoln \\ Nancy M. Lewis PhD RD, FADA \\ Professor, Department of Nutrition and Health Sciences, University of Nebraska-Lincoln
}

Kimberly B. Heidal PhD, RD

Assistant professor, Department of Nutrition, East Carolina University, Greenville, NC

Kent M. Eskridge PhD

Professor, Department of Statistics, University of Nebraska-Lincoln

Corresponding author - Paula K. Ritter-Gooder, 312 RLH, University of Nebraska-Lincoln, Lincoln, NE 68583-0806

\begin{abstract}
The purpose of this pilot study was to test the validity and reliability of a quantitative n-3 fatty acid food frequency questionnaire (FFQ) for later use with larger groups of individuals. A convenience sample of heart patients provided dietary data via three 24-hour food recalls and FFQs. Participants were women $(n=17)$ and men $(n=11), 43$ to 77 years of age. The association of mean daily intake of n-3 fatty acids obtained using food recalls and the FFQ was assessed by Pearson correlation. The reliability of the FFQ was assessed using coefficient a. Correlation of $\mathrm{n}-3$ fatty acid intake using the food recalls and the FFQ was $r=0.42(P<0.05)$. The coefficient a for the test-retest of the FFQ was .83. The top two foods, walnuts and flaxseed, contributed $58 \%$ of the n-3 fatty acid intake, and the third food, salmon, contributed $5 \%$. This quantitative n-3 FFQ is a valid instrument for use in place of food recalls for estimating n-3 fatty acid intakes in heart patients and is a reliable instrument to estimate n-3 fatty acid intakes from plant, animal, and seafood sources. The FFQ should be tested in a larger population. Registered dietitians can use this FFQ to screen for intakes, educate patients on food sources, and measure change in intakes after nutrition intervention.
\end{abstract}

Numerous studies have emphasized the importance of n-3 fatty acids in reducing the risk of cardiovascular disease. a-linolenic acid (ALA) (18:3n-3) is protective against ischemic heart disease and can favorably change vascular inflammation and endothelial dysfunction $(1,2)$. Both ALA and the longer chain eicosapentaenoic acid (EPA) (20:5n-3) and docosahexaenoic acid (DHA) (22:6n-3) have been shown to be protective against cardiovascular risk (1-10). n-3 fatty acids play an important role as structural membrane lipids, particularly in nerve tissue and the retina, and are precursors to eicosanoids. The reduced overall mortality observed in cardiovascular patients is related to a reduction in myocardial infarction and sudden death. Multiple mechanisms are improved lipoprotein profile, including inhibition of triglyceride synthesis, and diminished thrombogenicity. An increased intake of EPA and DHA results in increased circulatory levels of prostaglandins E3, which are anti-inflammatory, reducing incidence of cardiac arrythmias by promoting vasodilation and preventing clot formation.

Dietary Reference Intakes for Adequate Intakes for ALA were released by the National Academy of Sciences' Institute of Medicine in 2002 (11). The recommended Adequate Intake for ALA is $1.6 \mathrm{~g} /$ day for men aged 14 years to over 70 years and $1.1 \mathrm{~g} /$ day for women of the same age group to maintain optimal health in both sexes. In 2005, the American Dietetic Association issued The Disorders of Lipid Metabolism Evidence Based Nutrition Practice Guidelines (12). This evidence-based practice guideline recommends the inclusion of $\mathrm{n}-3$ fatty acids from both plant and marine dietary sources in a cardioprotective diet.

Dietary intake surveys in the Midwest United States indicate generally low n-3 fatty acid intakes (13). This is a result of infrequent fish consumption and lack of knowledge of other food sources. n-3 fatty acids are concentrated in fatty fish, flaxseed, walnuts, and certain oils, such as canola oil and walnut oil. Smaller amounts of n-3 fatty acids occur in a wide range of other plant and animal foods. Past surveys have used dietary recalls or frequency of fish consumption to estimate intakes $(3,4)$. Measuring only fish frequency in the diet limits total assessment of n-3 fatty acids because it does not include plant and animal sources of ALA. The purpose of this pilot study was to assess the validity and reliability of an n-3 fatty acid food frequency questionnaire (FFQ).

\section{Methods}

\section{Study Design and Population}

Participants were recruited from a Midwest regional heart clinic and had participated in a previous nutrition study (14). Patients were invited by telephone 3 months 
after the first study ended to participate in this study. All components of the study were approved by the Institutional Review Board.

\section{Dietary Intake Methods}

Two methods of dietary intake assessment were used; three 24-hour food recalls obtained by multiple-pass method (15), and FFQ. For the three 24-hour food recalls, a registered dietitian made an in-home visit and collected one of the recalls. Visual aids, such as food models, household measuring utensils, and pictures illustrating portion sizes, were used. Printed aids were left with the subjects to use in estimating food portion size for the 24-hour food recalls and FFQ that were collected later. Participants provided two additional 24-hour food recalls, including a weekend day. The registered dietitian collected these by telephone. Portion-size estimates were clarified and completeness of food recalls was assured by query.

The 152-item FFQ was developed from foods that provided $\geq 10 \mathrm{mg}$ n-3 fatty acid/medium serving using Food Processor (Version 8.1, 2003, ESHA Research, Salem, OR). ESHA Research uses US Department of Agriculture nutrient data sets as its core (16). Small, medium, and large portion sizes were defined for each food item, using the US Department of Agriculture Food Guide Pyramid portion guidelines (17). Frequency of consumption was categorized as none, once a month, less than once a week, one to two times a week, three to four times a week, five to six times a week, daily, and more than once a day. After the food recall, and while the registered dietitian was on site, the participant received instructions on how to complete the first FFQ. Additional pictures and food models were used to illustrate portion sizes for foods on the FFQ. For the second administration of the FFQ, participants were provided with a self-addressed envelope and instructed to complete and return the FFQ again in 2 weeks.

Food Processor was used to analyze the food recalls and to obtain total estimates of mean intake of ALA, DHA, and EPA. On the FFQ, estimated intake of total n-3 fatty acids was calculated for each food by multiplying the amount of n-3 fatty acids for that food by the frequency selected (as described above) by the selected serving size: small (0.5), medium (1.0), and large (1.5). n-3 fatty acid intakes and estimates of n-3 fatty acids by food group were estimated from the FFQ by the use of Microsoft Excel 2002 software (Microsoft Corp, Seattle, WA).

\section{Statistical Analysis}

Data were analyzed using Statistical Package for the Social Sciences (version 11.0, 2002, SPSS, Inc, Chicago, IL). Means and standard deviations for daily n-3 fatty acid intake were calculated for the food recalls and first administration of FFQ. Pearson correlation was used to assess the association between mean intakes as collected by 24-hour food recalls and first administration of FFQ. The mean difference between the first administration of the FFQ and 24-hour food recalls and the standard error of difference were estimated and tested with paired $t$ test. The a coefficient was used to assess the reliability of the FFQ using the first and second administrations of FFQ in the test-retest approach (18). The a coefficient of the FFQ measures the fraction of total variation that is a result of between-individual variability. A value near 1.00 means low within-person variation.

\section{Results}

Twenty-eight of 35 patients contacted agreed to participate ( $80 \%$ response rate). Two thirds were female, $7 \%$ were 43 to 50 years of age, 39\% were 51 to 60 years of age, and the remaining were between 62 and 77 years of age. More than two thirds were married, over $60 \%$ had annual incomes $\geq \$ 35,000$, and all were white. Mean daily intake of n-3 fatty acids by three 24-hour food recalls was 1.763 $\pm 1.949 \mathrm{~g}$ with a range of 0.210 to $8.150 \mathrm{~g} /$ day. Mean daily intake of n-3 fatty acids as assessed by first administration of FFQ was $2.468 \pm 1.927 \mathrm{~g}$ with a range of 0.340 to $7.638 \mathrm{~g}$. The difference between first administration FFQ and three 24-hour food recalls was $0.705 \mathrm{~g}$, with 0.393 standard error, and paired sample $t$ test indicated no significant difference between the two assessment methods $(P>0.05)$. Average time to complete the FFQ was 20 minutes. Pearson correlation between the food recalls and FFQ was $0.42(P<0.05)$. ALA contributed 84\% (1.48 g/day), EPA 5\% (0.08 g/day), and DHA $11 \%(0.20 \mathrm{~g} /$ day $)$ of the total n-3 fatty acid intakes from three 24-hour food recalls.

\section{A quantitative $F F Q$ would be useful to estimate intakes from fish, animal, and plant sources to identify individuals who need nutrition intervention.}

The a coefficient for the total daily n-3 fatty acid intake was .83. The a coefficient for food groupings ranged from .93 for grains to .57 for vegetables.

Table 1 shows the rank order of foods providing n-3 fatty acids in the diets from FFQ. Participants obtained n-3 fatty acids from a wide variety of food sources. The top 28 foods (shown in Table 1) provided $90 \%$ of the n-3 fatty acid intake. A total of 73 of 152 foods contributed $98 \%$ of the n-3 fatty acid intake. Overall, 113 of 152 items on the FFQ were consumed.

\section{Discussion}

Cardiovascular risk is negatively associated with increased intake of n-3 fatty acids (1-10). In addition, n-3 fatty acids may protect against cancer (19) and play a role in reducing inflammation in rheumatoid arthritis $(20,21)$. Because of these potential health benefits and the fact that n-3 fatty acid intakes are low in certain groups, a reliable and efficient method to estimate intake is needed. These heart patients had higher intakes of n-3 fatty acids by three 24-hour food recalls than previously reported. Three Midwestern populations had intakes of $1.060 \pm 0.300 \mathrm{~g} /$ day (low-income pregnant women) (22), $0.887 \pm 0.121 \mathrm{~g} /$ day (physically active adults) (23), and $0.620 \pm 0.710 \mathrm{~g} /$ day (volunteers with hypercholesterolemia) (24). Involvement in the earlier nutrition study may explain the higher intakes 
Table 1. Rank order of food sources a of n-3 fatty acids in 28 male and female cardiac patients from a Midwest regional heart clinic

\begin{tabular}{|c|c|c|c|}
\hline \multirow[b]{2}{*}{$\begin{array}{l}\text { Rank } \\
\text { order }\end{array}$} & \multirow[b]{2}{*}{ Food } & \multicolumn{2}{|c|}{ n-3 Fatty Acid Intake } \\
\hline & & $\begin{array}{l}\% \text { of } \\
\text { total }\end{array}$ & $\begin{array}{r}\text { Cumulative } \\
\%\end{array}$ \\
\hline 1 & English walnuts & 30.00 & 30.00 \\
\hline 2 & Ground flaxseeds & 27.81 & 57.81 \\
\hline 3 & Salmon & 4.92 & 62.73 \\
\hline 4 & Canola oil & 4.73 & 67.46 \\
\hline 5 & Uncle Sam cereal ${ }^{\mathrm{b}}$ & 2.98 & 70.44 \\
\hline 6 & Miracle Whip ${ }^{c}$ & 2.14 & 72.58 \\
\hline 7 & Soybeans & 1.84 & 74.42 \\
\hline 8 & Soy milk & 1.51 & 75.93 \\
\hline 9 & White bread & 1.46 & 77.39 \\
\hline 10 & Beef & 1.32 & 78.71 \\
\hline 11 & n-3 Egg & 1.16 & 79.87 \\
\hline 12 & Loose-leaf lettuce & 0.98 & 80.85 \\
\hline 13 & Chicken & 0.94 & 81.79 \\
\hline 14 & Almonds & 0.88 & 82.67 \\
\hline 15 & Banana & 0.75 & 83.42 \\
\hline 16 & Baked beans & 0.75 & 84.17 \\
\hline 17 & Tuna & 0.71 & 84.88 \\
\hline 18 & Cantaloupe/muskmelon & 0.70 & 85.58 \\
\hline 19 & Soy nuts & 0.67 & 86.25 \\
\hline 20 & Navy beans & 0.53 & 86.78 \\
\hline 21 & Potato & 0.46 & 87.24 \\
\hline 22 & Turkey & 0.44 & 87.68 \\
\hline 23 & Pecans & 0.42 & 88.10 \\
\hline 24 & Cheddar cheese & 0.41 & 88.51 \\
\hline 25 & Pork & 0.34 & 88.85 \\
\hline 26 & Zucchini squash & 0.34 & 89.19 \\
\hline 27 & Strawberries & 0.33 & 89.52 \\
\hline 28 & 1\% Milk & 0.31 & 89.83 \\
\hline
\end{tabular}

a. Food frequency questionnaire.

b. US Mills, Needham Heights, MA.

c. Kraft Foods, Northfield, IL.

in the heart patients in our study. Several studies have utilized a 62-item semi-quantitative FFQ including four fish categories to assess n-3 fatty acid intake $(6,7)$. However, the majority of previous studies have assessed n-3 fatty acid intake from fish consumption alone $(8,9)$. A quantitative FFQ would be useful to estimate intakes from fish, animal, and plant sources to identify individuals who need nutrition intervention.

The correlation between the recalls and FFQ was 0.42 . This compares favorably with the results of other validation studies. Other researchers have obtained correlation coefficients ranging from 0.40 to 0.70 for a variety of nutrients and among various population groups (25-27). Lower correlations occur for nutrients such as vitamin A (0.41), or vitamin E (0.19) because the amounts in food vary considerably.

Results of correlations between food recalls and FFQ in this study were similar to those reported in a previous study on the phytoestrogens, daidzein, and genistein contained in soy products. The correlations of diet recall and FFQ were 0.49 to 0.58 for diadzein and 0.45 to 0.54 for genistein (28). These dietary components are similar to the n-3 fatty acids in that they are concentrated in a few foods.

Because n-3 fatty acids occur in highly variable amounts among different foods, three 24-hour food recalls may not be enough days to reflect usual intake (25-27). A range of 54 days for males and 71 days for females is required to get within $\pm 10 \%$ accuracy, with a $95 \%$ confidence level for estimating fat intake, and vitamin A requires 40 days of food recalls (29). Although multiple dietary records are believed to provide the most accurate estimate of usual intakes, the number of records needed is large and was not feasible for this study. We chose three 24-hour food recalls to lower respondent burden.

Food recalls result in lower estimates of n-3 fatty acid intakes than the FFQ because of underreporting. When food recalls are used, consumption may be underreported by $10 \%$ to $45 \%$, and women are at a greater risk of underreporting than men $(30,31)$. Over two thirds of our subjects were women.

Estimates of intake using FFQs are generally higher than when food recalls are used. For example, pregnant women's energy and nutrient intakes were $30 \%$ to $40 \%$ higher with the FFQ than with food recalls (31). In our study, the FFQ estimate of total n-3 fatty acid intake was $29 \%$ higher than food recalls.

For test-retest reliability, results were comparable to other studies. We administered the FFQ 2 weeks apart to lessen measuring change in diet over time and maintain subject interest in the study. Our a coefficient of 0.83 was higher than 0.67 for vitamin E reported by Morris and colleagues (32) when using FFQs in Chicago Health and Aging Project participants. Erkkola and colleagues (33) measured 0.62 for n-3 fatty acids in the Finnish population using FFQs. The closer the a coefficient is to 1.00, the greater the internal consistency of items in the instrument being assessed. This demonstrates that each participant was able to estimate and give the same information on intake from one administration of the questionnaire to the next administration 2 weeks later. For food groupings, the a coefficients ranged from .93 for grains to .57 for vegetables between the two administrations of the FFQ. The variation in a coefficient among food groupings might be related to how frequently the same foods within that group are consumed. For example, grain items, such as sliced bread and breakfast cereal are relatively constant from one day to the next, whereas for vegetables, the type of vegetable within that grouping varied from day to day. The testretest coefficients for fats/oils, fish, legumes, and nuts and seeds were all $\geq .81$. These foods were major contributors to n-3 fatty acid intake.

The top two n-3 fatty acid food sources were walnuts and flaxseeds. Collectively these two foods provided $58 \%$ of the n-3 fatty acids in the form of ALA (Table). The third contributor to overall n-3 fatty acid intake was salmon, which provided nearly $5 \%$ of the total daily intake or 0.123 $\mathrm{g} /$ day. In this population, beef and the $\mathrm{n}-3$ egg each provided more $\mathrm{n}-3$ fatty acids than tuna $(1.32 \%$ and $1.16 \%$ of intake vs $0.71 \%$, respectively). Baked beans provided approximately the same amount of n-3 fatty acids as tuna. Tuna was the next fish item ranked after salmon. Clearly, 
the heart patients were not consuming fish as their top dietary source of n-3 fatty acids. Without affecting reliability, the FFQ may be improved by reducing the number of food items it contains.

The limitations of this study are the small number of subjects $(n=28)$, all of whom resided in the midwestern United States, the small number of 24-hour food recalls used (three recalls), and the short period between the testretest administration of the FFQ. Finally, the FFQ needs to be validated in a population with a wider range of ages and health conditions residing in different parts of the United States.

\section{Conclusions}

- This FFQ can be used to estimate n-3 fatty acid intakes in heart patients and requires additional testing before use in research. The number of food items may be reduced for use in future research and clinical settings.

- In these heart patients, the majority of n-3 fatty acid intake was provided by ALA from plant sources and a smaller amount of long chain EPA and DHA was provided by fish. Therefore, when assessing n-3 fatty acid intakes, registered dietitians need to use an assessment tool that includes plant, animal, and fish sources.

- Use of the FFQ can contribute to evidence-based practice by measuring outcomes of registered dietitian intervention to increase dietary intake of n-3 fatty acids.

Acknowledgments - This article is a contribution of the University of Nebraska Agricultural Research Division, Lincoln, NE 68583, Research Bulletin \#14574. This research was supported in part through the Hatch Act.

\section{References}

1. F.B. Hu, M.J. Stampfer, J.E. Manson, E.B. Rimm, A. Wolk, G.A. Colditz, C.H. Hennekens and W.C. Willet, Dietary intake of a-linolenic acid and risk of fatal ischemic heart disease among women, Am J Clin Nutr 69 (1999), pp. 890-897.

2. G. Zhoa, T.D. Etherton, K.R. Martin, S.G. West, P.J. Gillies and P.M. Kris-Etherton, Dietary a-linolenic acid reduces inflammatory and lipid cardiovascular risk factors in hypercholesterolemic men and women, J Nutr 134 (2004), pp. 2991-2997.

3. E. Dewailly, C. Blanchet, S. Gingras, S. Lemieux and B. Holub, Cardiovascular disease risk factors and n-3 fatty acid status in the adult population of James Bay Cree, Am J Clin Nutr 76 (2002), pp. 85-92.

4. A. Tavani, C. Pelucchi, E. Negri, M. Bertuzzi and C.L. Vecchia, n-3 polyunsaturated fatty acids, fish, and nonfatal acute myocardial infarction, Circulation 104 (2001), pp. 2269-2272.

5. H.C. Bucher, P. Hengstler, C. Schindler and G. Meir, N-3 polyunsaturated fatty acids in coronary heart disease: A meta-analysis of randomized controlled trials, Am J Med 112 (2002), pp. 298-304.
6. F.B. Hu, L. Bronner, W. Willet, M.J. Stampfer, K.M. Rexrode, C.M. Albert, D. Hunter and J.E. Manson, Fish and omega-3 fatty acid intake and risk of coronary heart disease in women, JAMA 787 (2002), pp. 1815-1821.

7. H. Iso, K.M. Rexrode, M.J. Stampfer, J.E. Manson, G.A. Colditz, F.E. Speizer, C.H. Hennekens and W.C. Willett, Intake of fish and omega-3 fatty acids and risk of stroke in women, JAMA 285 (2001), pp. 304-312.

8. I.A.B. Geelen, E.G. Schouten, A.C. Maan, M.B. Katan and P.L. Zock, Effects of n-3 fatty acids from fish on premature ventricular complexes and heart rate in humans, Am J Clin Nutr 81 (2005), pp. 416-420.

9. D. Mozaffarian, W.T. Longstreth, R.N. Lemaitre, T.A. Manolio, L.H. Kuller, G.L. Burke and D.S. Siscovick, Fish consumption and stroke risk in elderly individuals, Arch Intern Med 165 (2005), pp. 200-206.

10. M. Laidlaw and B.J. Holub, Effects of supplementation with fish oil-derived n-3 fatty acids and a-linolenic acid on circulating plasma lipids and fatty acid profiles in women, Am J Clin Nutr 77 (2003), pp. 37-42.

11. Food and Nutrition Board (FNB) and Institute of Medicine, of the National Academy of Science, Dietary Reference Intakes for Energy, Carbohydrates, Fiber, Fat, Protein and Amino Acids (Macronutrients). (2002) (2002); online at: http:// www.iom.edu/?id=21377

12. The American Dietetic Association, Evidence analysis library. The disorders of lipid metabolism evidence-based nutrition practice guideline (2005); online at http://www.ebg.adaevidencelibrary.com

13. N.M. Lewis, J.A. Albrecht, M.I. Schnepf, F.L. Hamouz, J.A. Driskell and J.A. Goertz, Meat choices and cookery methods of Nebraskans, J Foodservice Systems 8 (1995), pp. 165-174.

14. K. Heidal, N. Lewis and S. Evans, Survey of omega-3 fatty acid intakes and omega-3 food selections in cardiac patients living in a section of the Midwestern United States, Nutr Res 24 (2004), pp. 741-747.

15. J. Conway, L. Ingwersen, B. Vinyard and A. Moshfegh, Effectiveness of the US Department of Agriculture 5-step multiple-pass method in assessing food intake in obese and nonobese women, Am J Clin Nutr 77 (2003), pp. 1171-1178.

16. ESHA Research, Database (2006); online at http://www. esha.com/products/eshadata/database

17. Food Guide Pyramid. A Guide to Daily Food Choices. Washington, DC: US Department of Agriculture, Human Nutrition Information Service; 1992. Home and Garden Bulletin No. 252.

18. J.L. Fleiss, Design and Analysis of Clinical Experiments, Wiley, New York (1986).

19. S.C. Lasson, M. Kumlin, M. Ingelmen-Sundberg and A. Wolk, Dietary long-chain n-3 acids for the prevention of cancer: A review of potential mechanisms, Am J Clin Nutr 79 (2004), pp. 935-945.

20. C.S. Lau, K.D. Morley and J.J. Blech, Effects of fish oil supplementation on non-steroidal anti-inflammatory drug requirement in patients with mild rheumatoid arthritis - A double-blind placebo controlled study, Br J Rheumatol 32 (1993), pp. 982-989.

21. M.J. James and L.G. Cleland, Dietary n-3 fatty acids and therapy for rheumatoid arthritis, Semin Arthritis Rheum 27 (1997), pp. 85-97. 
22. N.M. Lewis, A.C. Widga, J.S. Buck and A.M. Frederick, Survey of omega-3 fatty acids in diets of Midwest low-income pregnant women, J Agromed 2 (1995), pp. 49-57.

23. C. Sindelar, S. Scheerger, S. Plugge, K. Eskridge, R.C. Wander and N.M. Lewis, Serum lipids of physically active adults consuming omega-3 fatty acid-enriched eggs or conventional eggs, Nutr Res 24 (2004), pp. 731-739.

24. N.M. Lewis, K. Schalch and S.E. Scheideler, Serum lipid responses to n-3 fatty acid enriched eggs in persons with hypercholesterolemia, J Am Diet Assoc 100 (2000), pp. 365-367.

25. G. Block and A.M. Hartman, Issues of reproducibility and validity of dietary studies, Am J Clin Nutr 50 (1989), pp. 1133-1138.

26. W. Willet, Nutritional Epidemiology (2nd ed), Oxford University Press, New York, NY (1998).

27. F.E. Thompson and T. Byers, Dietary assessment resource manual, J Nutr 124 (1994) (suppl 115), pp. 2245S-2317S.

28. M. Huang, G. Harrison, M. Mohamed, J. Gornbein, S. Henning, V. Go and F. Greendate, Assessing the accuracy of a food frequency questionnaire for estimating usual intake of phytoestrogens, Nutr Cancer 37 (2002), pp. 145-154.
29. P.P. Basiotis, S.O. Welsh, F.J. Cronin, J.L. Kelsay and W. Mertz, Number of days of food intakes records required to estimate individual and group nutrient intakes with defined confidence, J Nutr 117 (1987), pp. 1638-1641.

30. R.R. Briefel, C.T. Sempos, M.A. McDowell, S.C.Y. Chien and K. Alaimo, Dietary methods research in the Third National Health and Nutrition Examination Survey: Underreporting of energy intake, Am J Clin Nutr 65 (1997), pp. 1203-1209.

31. G.M. Price, A.A. Paul, T.J. Cole and M.E.J. Wadsworth, Characteristics of the low-energy reporters in a longitudinal national dietary survey, Br J Nutr 77 (1977), pp. 833-851.

32. M.C. Morris, C.C. Tangney, J.L. Bienias, D.A. Evans and R.S. Wilson, Validity and reproducibility of a food frequency questionnaire by cognition in an older biracial sample, Am J Epidemiol 158 (2003), pp. 1213-1217.

33. M. Erkkola, M. Karppinen, J. Javarainen, L. Rasanen, M. Knip and S.M. Virtanen, Validity and reproducibility of a food frequency questionnaire for pregnant Finnish women, Am J Epidemiol 151 (2001), pp. 466-476. 